Maria Huertas Vaquero

María Ángeles Asencio

Egea

Rafael Carranza Gonzále ${ }^{21}$

Antonio Padilla Serrano ${ }^{2}$

Maria Carmen Conde

García $^{3}$

José Maria Tenias Burillo 4

Olga Redondo González ${ }^{4}$

\section{Association between antibiotic pressure and the risk of colonization/infection by multidrug-resistant Acinetobacter baumannii complex: a time series analysis}

Article history

Received: 8 April 2021; Revision Requested: 16 July 2021; Revision Received: 31 July 2021; Accepted: 19 August 2021; Published: 6 October 2021

\section{ABSTRACT}

Introduction. To analyze the association between antibiotic pressure and the risk of colonization/infection by Acinetobacter baumannii complex (AB), evaluating both the individual and general prescriptions of antibiotics.

Methods. This is an analytical, observational, case-control study on patients admitted to an Intensive Care Unit (ICU) during an AB outbreak (14 months). A five-year time series was constructed with the monthly incidence of cases of infection/colonization with strains of $A B$ resistant to each antibiotic administered and with the monthly consumption of these antibiotics in the ICU.

Results. We identified 40 patients either infected (23) or colonized (17) by $A B$ and 73 controls. We found an epidemic multidrug-resistant clone of $A B$ in $75 \%$ of cases. Risk factors associated with the development of $A B$ infection/colonization were: greater use of medical instruments, the presence of a tracheostomy, cutaneous ulcers, surgical lesions and prior antibiotic therapies. The regression analysis of individual use of antibiotics showed that prior treatment with ceftazidime, ceftriaxone, amoxicillin/clavulanate, imipenem, levofloxacin, linezolid, and vancomycin was a risk factor for acquiring $A B$. ARIMA models showed that the relationship were greatest and statistically significant when the treatment occurred between 6 months (ceftazidime) and 9 months (imipenem and levofloxacin) prior.

Conclusions. The dynamic and aggregate relationship between the incidence of infection/colonization by multidrugresistant strains of $A B$ and prior antibiotic treatment was statistically significant for intervals of 6 to 9 months.

Keywords: Acinetobacter baumannii complex; time series analysis; casecontrol study; antibiotics prescription; outbreak

Correspondence:

Maria Ángeles Asencio Egea

Hospital General La Mancha Centro

Avenida de la Constitución 3

13600 Alcázar de San Juan, Ciudad Rea

E-mail:marian_asencio@yahoo.es

\section{Asociación entre la presión antibiótica y el riesgo de colonización/infección por Acinetobacer baumannii complex multirresistente: análisis de series temporales}

\section{RESUMEN}

Introducción. Analizar la asociación entre la presión antibiótica y el riesgo de colonización/infección por Acinetobacter baumannii complex (AB), evaluando tanto las prescripciones individuales como las prescripciones generales de antibióticos.

Métodos. Estudio analítico, observacional, de casos y controles en pacientes ingresados en una Unidad de Cuidados Intensivos (UCI) durante un brote de $A B$ de 14 meses de duración. Se construyó una serie temporal de cinco años con la incidencia mensual de casos de infección/colonización por cepas de $A B$ resistentes a cada antibiótico administrado y con el consumo mensual de estos antibióticos en la UCl.

Resultados. Identificamos 40 pacientes infectados (23) o colonizados (17) por $A B$ y 73 controles. Encontramos un clon epidémico de $A B$ multirresistente en el 75\% de los casos. Los factores de riesgo asociados con la infección/colonización por AB fueron: el mayor uso de instrumentos médicos, la presencia de traqueotomía, úlceras cutáneas, lesiones quirúrgicas y las terapias antibióticas previas. El análisis de regresión del uso individual de antibióticos mostró que el tratamiento previo con ceftazidima, ceftriaxona, amoxicilina-clavulánico, imipenem, levofloxacino, linezolid y vancomicina fue un factor de riesgo para adquirir $A B$. Los modelos ARIMA mostraron que la relación fue mayor y estadísticamente significativa cuando el tratamiento se produjo entre los 6 meses previos para ceftazidima y los 9 meses anteriores para imipenem y levofloxacino.

Conclusiones. La relación dinámica y agregada entre la incidencia de infección/colonización por cepas de $A B$ 
multirresistente y el tratamiento antibiótico previo fue estadisticamente significativa para intervalos de 6 a 9 meses.

Palabras clave: Acinetobacter baumannii complex; análisis de series temporales; estudio de casos-controles; consumo de antibióticos; brote

\section{INTRODUCTION}

In the past few decades, Acinetobacter baumannii complex $(A B)$ has emerged as a microorganism capable of producing various types of nosocomial infections, mainly of the respiratory system (pneumonias), bacteremia, of the skin and soft tissue, and meningitis [1]. The risk of colonization and infection by $A B$ is associated with factors such as staying in specific types of hospital units, a prolonged hospital stay, the presence of serious underlying disease, the use of mechanical ventilation, invasive interventions (catheter probes), and prior antibiotic pressure/treatment [2,3]. In turn, $A B$ infection/ colonization leads to increases in morbidity, length of hospital stays, and cost [4].

$A B$ is a microorganism endemic to some hospital centers and is responsible for numerous nosocomial outbreaks throughout the world [5]. Its heightened ability to spread is due to various factors, including its ability to develop resistance to antimicrobial substances [6]. In the past decade, researchers have detected the emergence of multi-drug resistant strains of $A$. baumannii complex (MDR-AB) [7], as well as pan-resistant strains [8], both due to selective antibiotic pressure from the use of wide-spectrum antibiotics as well as to patient-to-patient transmission of drug-resistant strains of the microorganism [9].

The goal of our work was to analyze the association between antibiotic pressure and the risk of infection/ colonization by $A B$, examining both the individual prescriptions of antimicrobials as well as the more general use of antibiotics during an outbreak in the ICU of a Spanish hospital.

\section{METHODS}

Ethical approval. This study was approved by the Institutional Review Board of La Mancha Centro General Hospital (HGMC). The research was conducted in accordance with the Declaration of Helsinki and national and institutional standards.

Setting. This study was conducted in a multipurpose Intensive Care Unit (ICU) of a rural Spanish Hospital which provides healthcare to a population of approximately 210,000 inhabitants. The ICU has 10 beds for adult patients, who receive care from health care professionals specialized in Intensive Care Medicine.

Study design and patient selection. This analytical, observational, matched case-control study was carried out during an $A B$ outbreak occurred in this particular ICU (14 months during the years 2010 and 2011, although sporadic cases were detected in the following years; therefore this strain has remained endemic in the hospital). The matched case- control design allows us to analyze and compare significantly different cases as long as they are matched to similar controls.

The study included a total of 40 cases and 73 controls. The cases were defined as patients admitted to the ICU during the outbreak and in whom $A B$ infection/colonization was detected through the isolation of this microorganism in clinical samples and/or epidemiological surveillance cultures. The clinical significance of colonization or infection by the $A B$ isolates and the type of infection developed in each case was established by means of the criteria proposed by the Centers for Disease Control and Prevention (CDC) [10]. The controls were defined as patients admitted to the ICU during the same period as the cases (usually on the same day and sometimes in the same week) that developed neither an $A B$ infection nor colonization. Two controls were selected for each case in order to allow the detection of odds ratios (ORs) greater than or equal to 2 with a power of $80 \%$ and an alpha risk of 5\% (95\% confidence interval, $\mathrm{Cl}$ ).

Data collection. The following information was collected from the patients' clinical histories and the data base of the ICU: patient age, sex, and origin (home, another hospital, or an old-age residence facility); time interval between admission to the ICU and the appearance of $A B$ infection/ colonization; mechanical ventilation; tracheotomy; presence of surgical lesions or skin ulcers; use of invasive procedures or instruments such as central venous catheters, drainage tubes, urinary probes, and/or nasogastric probes; parenteral feeding; underlying illnesses such as diabetes mellitus, neoplasia, chronic pulmonary disease, chronic kidney disease, heart disease, chronic liver disease, chronic neutropenia, parenteral drug addiction; Charlson Index as an indicator of associated comorbidities; patient condition as measured with the APACHE Il scale; and any prior antibiotic therapies.

The data on antimicrobial use was obtained from the database of the hospital Pharmacy Department. Cases that had received prior antibiotic therapies were defined as those having been administered antimicrobials during the period between admission to the ICU until the isolation of an $A B$ strain in clinical samples or surveillance cultures. For patients in the control group, prior antibiotic treatment was defined as the use of antibiotics from the time of admission to the ICU until the isolation of an $A B$ strain in their matching case. Antibiotic agents were grouped pharmacologically according to the widely accepted Anatomical Therapeutic Chemical Classification, developed by the Nordic Council of Medicines, which allows for comparisons between distinct active principals or groups [11].

Two parameters were studied regarding exposure levels to antibiotics: the accumulated dose and the average treatment potency. The Defined Daily Dose (DDD) was used as a unit to measure the prescription of antimicrobials and to compare the effects of the accumulated dose and the treatment potency (DDD/day).

Microbiological studies. Identification of the $A B$ strain phenotypes was carried out in the microbiology laboratory 
of the HGMC with the aid of an automated Vitek-2 system (BioMérieux ${ }^{\circledR}$ France). Confirmation of the identification, along with the clonality analysis carried out with pulsed-field gel electrophoresis, was performed after deoxyribonucleic acid digestion with the Apal enzyme (Takara, Shiga, Japan) at the National Center for Microbiology [12], by using a clamped homogeneous electric field electrophoresis apparatus (BioRad Laboratories, Hercules, CA). The study of antimicrobial sensitivity was carried out in the microbiology laboratory of the HGMC by means of microdilution, performed with the automated Vitek-2 system in accordance with the norms described in the Clinical and Laboratory Standards Institute.

We isolated MDR-AB as a strain showing resistance to at least one agent of three or more of the following classes of antimicrobials: broad spectrum cephalosporins (ceftazidime or cefepime), carbapenems (imipenem or meropenem), ampicillin/ sulbactam, antipseudomonal penicillins with beta-lactamase inhibitors (piperacillin-tazobactam), fluoroquinolones (ciprofloxacin or levofloxacin), aminoglycosides (gentamycin, tobramycin, or amikacin), colistin, and tetracyclines [13].

Prevention and infection control. An $A B$ infection/ colonization surveillance system was established to prevent cross-transmission by health personnel. Infection control methods included strict environmental cleaning (1:10 sodium hypochlorite dilution), effective sterilization of reusable medical equipment, staff formation on proper hand hygiene practices and use of contact precautions, strict patients isolation and surveillance and environmental cultures, together with effective antibiotics stewardship programs. In a nosocomial outbreak context, locating the source of infection and hospital Unit closure are often essential in order to eradicate it [14].

\section{Statistical analysis.}

A. Descriptive phase. The incidence of cases of $A B$ infection/colonization during the outbreak was calculated as accumulated incidence (the ratio between the number of detected cases and total ICU admissions).

B. Bivariate analysis. The response variable (case/control) was related to each of the independent variables by constructing contingency tables. For each table we estimated the statistical significance (chi-square test or Fisher exact test if the expected number of events was less than 5) for categorical variables and t-student test for continuous variables and measured the magnitude of the association as $\mathrm{OR}$ and $95 \% \mathrm{Cl}$.

C. Multivariate analysis. All independent variables that were associated with the response variable with a significance of $p<0.20$ formed part of the multivariate models of conditional logistic regression. We use a significant change $(p<0.05)$ in the likelihood of the model as input criteria in the final models.

Statistical calculations were made with the aid of the STATA program, version 11.0 (StataCorp LP, Texas, USA).

D. Time series analysis: ARIMA (autoregressive integrated moving average models). Although outbreak lasted 14 months, sporadic cases were detected in the

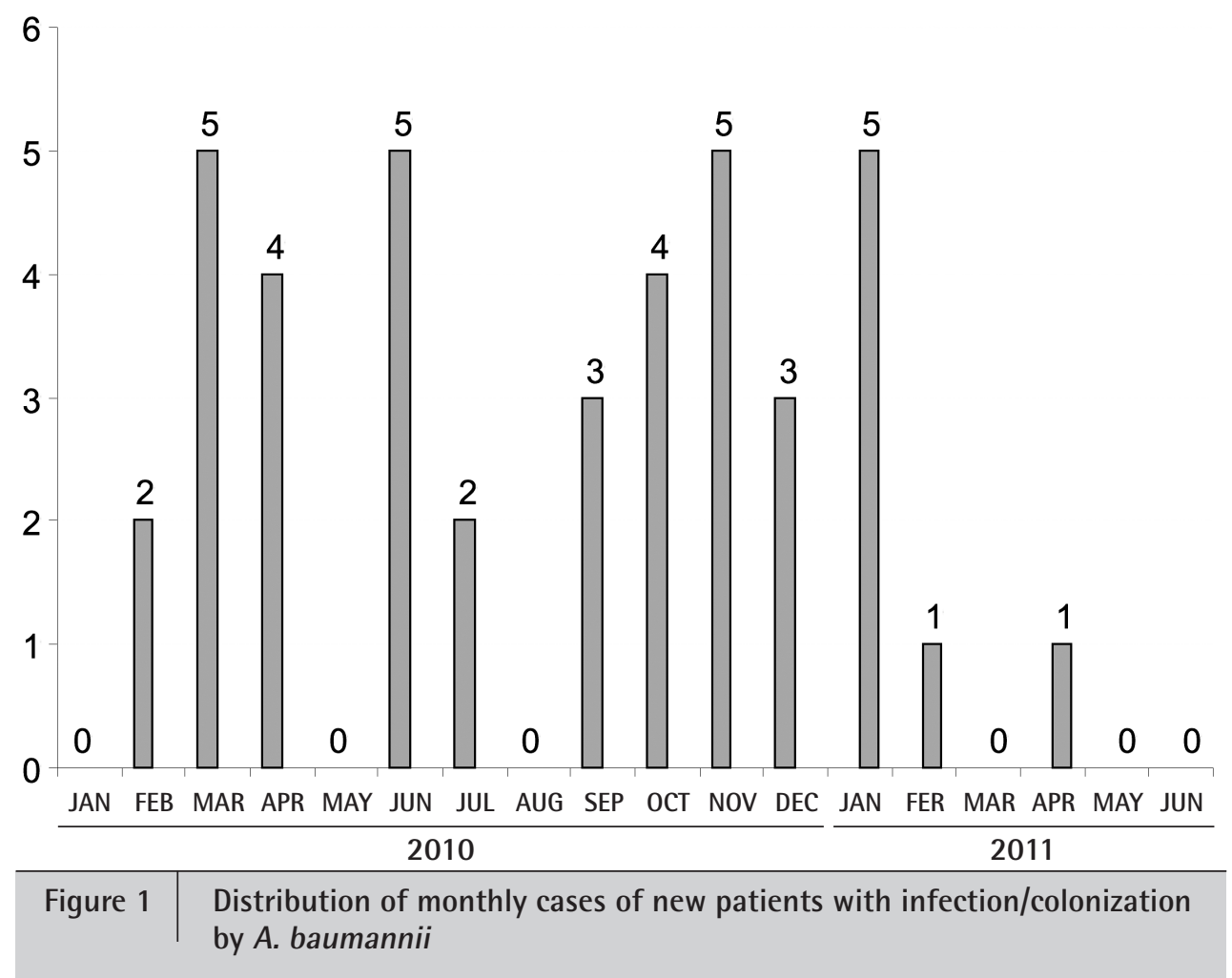




\begin{tabular}{|c|c|c|c|c|}
\hline \multirow[t]{2}{*}{ Table 1} & \multicolumn{4}{|c|}{$\begin{array}{l}\text { Demographic and clinical data for cases } \\
\text { and controls }\end{array}$} \\
\hline & & Cases $(n=40)$ & Controls $(n=73)$ & p \\
\hline \multicolumn{2}{|l|}{ Age, media \pm SD } & $61.5 \pm 15.2$ & $65.3 \pm 16.2$ & $0.23^{\mathrm{a}}$ \\
\hline \multicolumn{2}{|l|}{ Sex, $n(\%)$} & & & $0.23^{b}$ \\
\hline \multicolumn{2}{|l|}{ Men } & $26(65 \%)$ & $39(53.4 \%)$ & \\
\hline \multicolumn{2}{|l|}{ Women } & $14(35 \%)$ & $34(46.6 \%)$ & \\
\hline \multicolumn{2}{|l|}{ Origen, $n(\%)$} & & & $0.018^{\mathrm{b}}$ \\
\hline \multicolumn{2}{|l|}{ Home } & $28(70 \%)$ & $65(89 \%)$ & \\
\hline \multicolumn{2}{|l|}{ Another Hospital } & $12(30 \%)$ & $7(9.6 \%)$ & \\
\hline \multicolumn{2}{|l|}{ Nursing homes } & - & $1(1.4 \%)$ & \\
\hline \multicolumn{2}{|l|}{ Prior admission, $n(\%)$} & & & $0.09^{b}$ \\
\hline \multicolumn{2}{|l|}{ No } & $9(22.5 \%)$ & $28(38.4 \%)$ & \\
\hline \multicolumn{2}{|l|}{ Yes } & $31(77.5 \%)$ & $45(61.6 \%)$ & \\
\hline \multicolumn{2}{|c|}{ Charlson Index score, media \pm SD } & $0.74 \pm 0.99$ & $0.92 \pm 1.11$ & $0.42^{\mathrm{a}}$ \\
\hline \multicolumn{2}{|c|}{ APACHE II Severity Index score, media \pm SD } & $20.3 \pm 9.1$ & $12.6 \pm 8.5$ & $<0.001^{\mathrm{a}}$ \\
\hline
\end{tabular}

SD: standard deviation; ${ }^{a}$ t-student test; ${ }^{b} \times 2$ test

following years. Therefore, a five-year time series (including the 14 months of the outbreak) was constructed with the monthly incidence of cases of infection/colonization with strains of $A B$ resistant to each antibiotic administered and with the monthly consumption of these antibiotics in the ICU. Each time series was modeled for the construction of different ARIMA models according to the method adapted by Monet and Lozano [15]. Therefore, these models allowed us to determine a possible association between the antibiotic consumption and the appearance of cases of infection/colonization by resistant $A B$ strains, as well to estimate the time interval in which this occurred. The delays for which the association between consumption and resistance was more significant were identified by means of cross-correlation graphs.

\section{RESULTS}

We found 40 patients infected or colonized by $A B$ during their stay in the ICU (figure 1). The analysis of $A B$ strains by means of pulsed-field gel electrophoresis detected the presence of 6 circulating clones, with one prevalent epidemic clone of MDR-AB in 30 of the 40 patients (clone 1). Of the 40 patients, 23 (57.5\%) developed various types of infections while 17 (42.5\%) were colonized solely by this microorganism. The overall incidence of $A B$ infection/colonization in The ICU during the outbreak was 9.0 cases per 1000 patients/day (Cl95\%: 6.5-12.3 cases per 1000 patients/day). In the years following the outbreak, new cases of $A B$ infection/colonization appeared sporadically, making it necessary to maintain appropriate policies for controlling nosocomial infection in our hospital.

\begin{tabular}{|c|c|c|c|c|}
\hline \multirow[t]{2}{*}{ Table 2} & \multicolumn{4}{|c|}{$\begin{array}{l}\text { Risk factors associated with infection/ } \\
\text { colonization of Acinetobacter baumannii } \\
\text { complex during a nosocomial outbreak }\end{array}$} \\
\hline & & $\begin{array}{l}\text { Cases } \\
(n=40)\end{array}$ & $\begin{array}{c}\text { Controls } \\
(n=73)\end{array}$ & $p^{a}$ \\
\hline \multicolumn{5}{|c|}{ Intrinsic Factors } \\
\hline Alcoholis & & $4(10 \%)$ & $4(5.5 \%)$ & 0.45 \\
\hline \multicolumn{2}{|c|}{ Parenteral Drug Addiction } & $1(2.5 \%)$ & - & 0.35 \\
\hline \multicolumn{2}{|c|}{ Liver Disease } & $2(5 \%)$ & - & 0.12 \\
\hline \multicolumn{2}{|c|}{ Chronic Renal Failure } & $10(25 \%)$ & $9(12.3 \%)$ & 0.09 \\
\hline \multicolumn{2}{|c|}{ Heart Disease } & $10(25 \%)$ & $14(19.2 \%)$ & 0.48 \\
\hline \multicolumn{2}{|c|}{ Chronic Obstructive Lung Disease } & $8(20 \%)$ & $6(8.2 \%)$ & 0.08 \\
\hline \multicolumn{2}{|c|}{ Neoplasia } & $2(5 \%)$ & $6(8.2 \%)$ & 0.71 \\
\hline \multicolumn{2}{|c|}{ Diabetes mellitus } & $10(25 \%)$ & $22(30.1 \%)$ & 0.56 \\
\hline \multicolumn{2}{|c|}{ Neutropenia } & $1(2.5 \%)$ & - & 0.35 \\
\hline \multicolumn{2}{|l|}{ Obesity } & $9(22.5 \%)$ & $10(13.7 \%)$ & \\
\hline \multicolumn{5}{|c|}{ Extrinsic Factors } \\
\hline \multicolumn{2}{|c|}{ Central venous catheter } & $40(100 \%)$ & $19(26 \%)$ & $<0.001$ \\
\hline \multicolumn{2}{|c|}{ Parenteral feeding } & $16(40 \%)$ & $2(2.7 \%)$ & $<0.001$ \\
\hline \multicolumn{2}{|c|}{ Urinary probe } & $40(100 \%)$ & $27(37 \%)$ & $<0.001$ \\
\hline \multicolumn{2}{|c|}{ Nasogastric probe } & $34(85 \%)$ & $14(19.2 \%)$ & $<0.001$ \\
\hline \multicolumn{2}{|c|}{ Mechanical ventilation } & $35(87.5 \%)$ & $12(16.4 \%)$ & $<0.001$ \\
\hline \multicolumn{2}{|c|}{ Tracheotomy } & $7(17.5 \%)$ & - & $<0.001$ \\
\hline \multicolumn{2}{|l|}{ Drains } & $20(50 \%)$ & $9(12.3 \%)$ & $<0.001$ \\
\hline \multicolumn{2}{|c|}{ Surgical lesion } & $17(42.5 \%)$ & $9(12.3 \%)$ & $<0.001$ \\
\hline \multicolumn{2}{|c|}{ Skin lesion or ulcer } & $16(40 \%)$ & $2(2.7 \%)$ & $<0.001$ \\
\hline \multicolumn{2}{|c|}{ Prior antibiotic therapy } & $40(100 \%)$ & $29(39.7 \%)$ & $<0.001$ \\
\hline
\end{tabular}

${ }^{a} \chi 2$ test

In both the cases and the controls there was a predominance of men over women, with a median age of 60 years (Table 1 ). The two groups presented with a similar frequency of comorbidities (data no shown) and with a low final Charlson Index score with no statistically significant differences $(0.74 \pm 0.99$ vs. $0.92 \pm 1.11 ; p=0.42)$. In contrast, the APACHE severity index was significantly higher in the cases than in controls $(20.3 \pm 9.1$ vs. $12.6 \pm 8.5 ; p<0.001)$ (Table 1).

The cases presented with a higher prevalence of intrinsic risk factors for developing a nosocomial infection, although the difference did not reach statistical significance. The risk factors associated with the development of $A B$ infection/ colonization found in our study were: mechanical ventilation; parenteral feeding; greater invasive devices, such as the use of CVCs, probes, and drains; the presence of a tracheostomy, cutaneous ulcers or surgical lesions; and prior antibiotic treatments (Table 2). 


\begin{tabular}{|c|c|c|c|c|c|c|}
\hline Table 3 & \multicolumn{6}{|c|}{$\begin{array}{l}\text { Bivariate analyses of the individual } \\
\text { use of antimicrobials overall and on a } \\
\text { daily basis in cases and controls and its } \\
\text { association with colonization/infection by } \\
\text { Acinetobacter baumannii complex during } \\
\text { a nosocomial outbreak }\end{array}$} \\
\hline \multirow[t]{2}{*}{ Antibiotic } & & \multicolumn{2}{|c|}{ Controls } & \multicolumn{3}{|c|}{ Cases } \\
\hline & & Media & SD & Media & SD & $p^{a}$ \\
\hline \multirow[t]{2}{*}{ Amoxicillin/Clavulanat } & DDD & 0.3 & 1.3 & 1.1 & 2.2 & 0.047 \\
\hline & $\mathrm{DDD} /$ day & 0.1 & 0.3 & 0.3 & 0.5 & 0.051 \\
\hline \multirow[t]{2}{*}{ Ceftazidime } & DDD & 0.0 & 0.0 & 0.4 & 2.1 & 0.230 \\
\hline & $\mathrm{DDD} /$ day & 0.0 & 0.0 & 0.1 & 0.3 & 0.040 \\
\hline \multirow[t]{2}{*}{ Ceftriaxone } & DDD & 0.4 & 1.7 & 3.5 & 6.5 & 0.005 \\
\hline & $\mathrm{DDD} /$ day & 0.1 & 0.5 & 0.7 & 1.0 & 0.004 \\
\hline \multirow[t]{2}{*}{ Imipenem } & DDD & 0.0 & 0.0 & 2.5 & 5.9 & 0.011 \\
\hline & $\mathrm{DDD} /$ day & 0.0 & 0.0 & 0.3 & 0.6 & 0.004 \\
\hline \multirow[t]{2}{*}{ Levofloxacin } & DDD & 0.1 & 0.5 & 2.7 & 6.2 & 0.012 \\
\hline & DDD/day & 0.1 & 0.2 & 0.4 & 0.7 & 0.003 \\
\hline \multirow[t]{2}{*}{ Linezolid } & DDD & 0.0 & 0.0 & 1.5 & 4.6 & 0.047 \\
\hline & $\mathrm{DDD} /$ day & 0.0 & 0.0 & 0.2 & 0.4 & 0.002 \\
\hline \multirow[t]{2}{*}{ Vancomycin } & DDD & 0.0 & 0.2 & 1.4 & 3.2 & 0.009 \\
\hline & $\mathrm{DDD} /$ day & 0.0 & 0.1 & 0.2 & 0.4 & 0.003 \\
\hline
\end{tabular}

SD: standard deviation; ${ }^{a}$-student test

In general, greater antibiotic pressure was observed in cases than in controls. All the cases had received previous antibiotic treatment compared to only one of every three controls. The regression analysis of individual use of antibiotics showed that prior treatment with ceftazidime, ceftriaxone, amoxicillin/clavulanate, imipenem, levofloxacin, linezolid, and vancomycin was a risk factor for acquiring $A B$. This association was observed in both measurements of antibiotic exposure studied (DDD and DDD/day) (Table 3).

Likewise, when analyzed by group of antibiotics, prior treatment with carbapenems, third-generation cephalosporins, penicillins with beta-lactamase inhibitors, glycopeptides, quinolones, and aminoglycosides constituted a risk factor for acquiring $A B$. These differences remained even after adjusting for patient age and the severity of infection. This association was observed in both measurements of antibiotic exposure studied (Table 4).

The results of the ecological analysis of the association between antibiotic pressure in the ICU and the appearance of resistant strains of $A B$ (by means of ARIMA models) show that the relationship was greatest and statistically significant when the treatment had occurred between 6 months (ceftazidime) and 9 months (imipenem and levofloxacin) prior (Table 5).

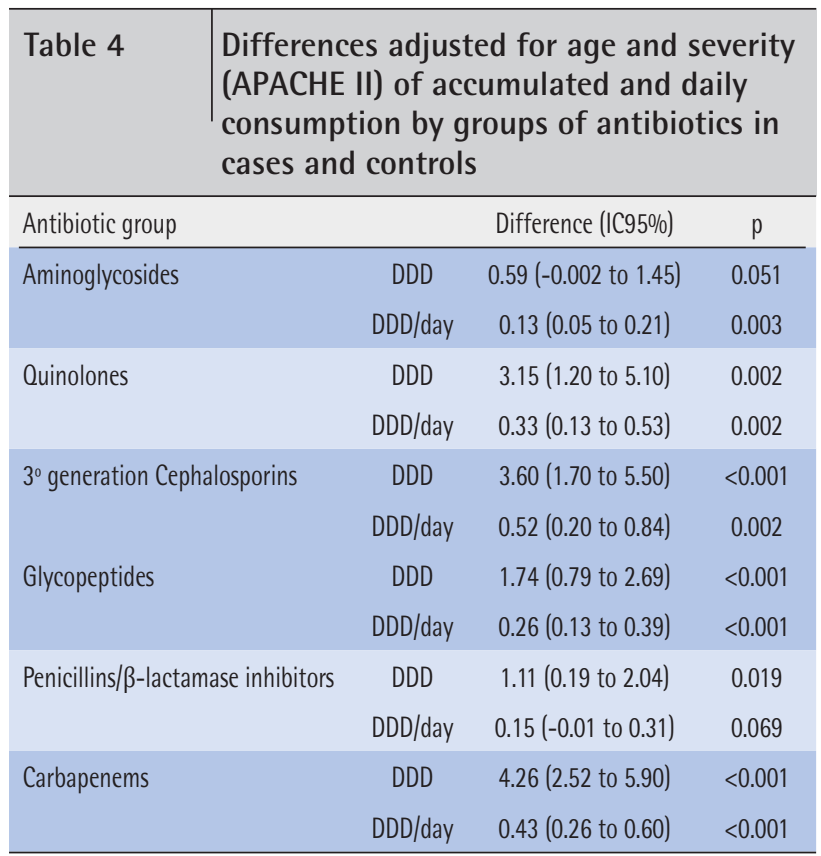

Differences adjusted by means of multiple lineal regression

\begin{tabular}{l|lllc}
\hline Table 5 & $\begin{array}{l}\text { ARIMA model parameters of the dynamic } \\
\text { relationship between prior antibiotic } \\
\text { treatment and the development of } \\
\text { infection/colonization of a resistant strain } \\
\text { of Acinetobacter baumannii complex }\end{array}$ \\
\hline Antibiotic & ARIMA model & Time interval (months) & Coefficient (SE) & $p$ \\
\hline Ceftazidime & $(1,0,0)$ & 6 & $0.446(0.127)$ & 0.001 \\
Imipenem & $(1,0,0)$ & 9 & $0.026(0.006)$ & $<0.001$ \\
Levofloxacin & $(1,0,0)$ & 9 & $0.225(0.151)$ & 0.14 \\
\hline
\end{tabular}

SE: standard error

\section{DISCUSSION}

Our results show that prior antibiotic treatment is an important risk factor for infection/colonization by $A B$. Previous use of the antimicrobials analyzed acted like a risk factor regardless of patient age or disease severity in the acquisition of $A B$ infection/colonization. The dynamic and aggregate relationship between the incidence of infection/ colonization by antibiotic resistant $A B$ strains and prior antibiotic treatment was significant for intervals of 6 to 9 months.

We also found that disease severity (as measured with APACHE II criteria), along with the presence of catheters, drains, probes, and mechanical ventilation, all were risk factors associated with $A B$ infection/colonization. The use of invasive procedures may give rise to colonization/infection by opportunistic bacteria such as Acinetobacter sp., and have 
previously been identified as risk factors for the acquisition of this particular microorganism [16-18].

The use of broad-spectrum antibiotics can displace the bacterial flora of patients, thus facilitating colonization/ infection by antibiotic resistant strains such as $A B$. In fact, previously published studies have demonstrated that prior exposure to certain antimicrobials such as third-generation cephalosporins heightens the risk of $A B$ infection/colonization $[17,19,20]$. This is also true of exposure to carbapenems $[17,21,22]$, fluoroquinolones [17,23], aminoglycosides [17], and glycopeptides [9]. Unfortunately, none of these studies adequately analyzed the dynamic nature of the evolution of resistance in this microorganism in order to establish the time relationship between prior treatment with various antimicrobials and the subsequent development of resistant $A B$ strains [15]. In this sense, it would be helpful to establish analysis protocols to examine the evolution of resistance over prolonged periods of time (minimum: 5 years) by analyzing the small variations that occur within shorter time intervals (monthly). Such studies would allow us to describe the current state of resistance as well as to predict future developments from data on the use of antibiotics in a given setting [15]. With this aim in mind, we conducted a time series analysis to allow us to assess the dynamic relationship between global use of antibiotics in the ICU and the appearance of $A B$ strains that were resistant to each particular antibiotic. This method allowed us to observe how the associations reached their peak and became statistically significant for time intervals of 6 months for ceftazidime and 9 months for imipenem and levofloxacin.

The evolution of resistance thus seems to be associated with prior antibiotic treatment occurring 6 to 9 months before the appearance of resistant $A B$ strains. Previously published ecological studies have associated the increase in the prevalence of pan-resistant $A B$ with increases in the use certain antibiotics such as carbapenems [24] in a given hospital unit; others have described how the increase in Acinetobacter spp. resistant to meropenem was significantly associated with the increased use of broad spectrum cephalosporins [25]. However, these ecological studies used annual rather than monthly aggregates, making it difficult to establish a better understanding of both this association as well as the time frame in which resistance appears. Nowadays, MDR-AB is a matter of growing concern and various studies, based on time series, analyze the influence of antibiotic pressure on the appearance of resistant gram-negative bacilli to cephalosporines and carbapenems, including $A B[26,27]$.

This method of analysis has allowed us to overcome several methodological limitations found in prior research. Although several previously published studies have examined the association between the use of antibiotics and infection/ colonization by various multi-drug resistant microorganisms such as AB $[28,29]$, few have used measurements of cumulative dose or therapeutic potency to study how this relationship is affected by prior exposure to antibiotics [22]. In our study we have collected accurate information about antibiotic exposure, using DDD as a unit of measurement to assess the effect of cumulative dose and therapy potency (DDD/day) in the acquisition of $A B$. In addition, whereas other studies have found that from the point of view of the dose-response effect, therapy potency was the measurement of antibiotic exposure that presented the greatest association with the highest ORs [22], our results show an association for both of the indicators studied (the cumulative dose, or DDD, and the therapeutic potency, or DDD/day), although the association was greater for the latter. We feel that this information could be useful when designing therapeutic regimens, not only for knowing whether the use of a given antibiotic is related to the appearance of $A B$, but also for calculating which of the two variables is more important in this process.

One of the limitations of our study is the inclusion of asymptomatic, but colonized patients within the case group. This inclusion could be considered inappropriate by some researchers; however, following the criteria of previous authors $[8,22]$, we have decided to include them, considering colonization to be a precursor to $A B$ infection and also because these patients tend to constitute an important transmission reservoir. We likewise feel that including the active epidemiological surveillance culture samples provides valuable information on colonization, allowing us to overcome the limitations of prior studies that only include data on $A B$ isolated in clinical samples. Such studies may have thus mistakenly considered colonized patients with no clinical manifestations to have been controls [30].

The paired case-control design allowed us to minimize, if not wholly eliminate, the effect of confounding variables, (the ICU personnel, equipment and organizational aspects, infection control and prevention, or colonization pressure in the ICU), since these were the same for each case and its two paired controls, so that the risk of infection is similar. Given the small size of our ICU, it would be recommended to verify these results in ICUs with a greater number of beds.

Our work has important practical implications since it allows for the identification of the causal factors associated with this type of infection, some of which are modifiable, such as antibiotic pressure. The restriction of the use of broadspectrum antimicrobials (whenever possible) and antibiotic rotation policies are both measures aimed at the rational use of antimicrobials to reduce the evolution of resistant strains [31]. It would be advisable to carry out a multicenter study to confirm the consistency of our findings on the dynamic relationship between antibiotic pressure and the outbreak of a resistant $A B$ and to find out whether a separate relationship exists in other centers, either within a 6 to 9 -month timeframe or a similar interval. This would allow us to elaborate predictive models to help elucidate and manage the antibiotic policies of each hospital.

In conclusion, our results verify that the epidemic distribution of a microorganism such as $A B$ can be predicted, monitored, and its causes known in a hospital setting. We have also demonstrated the association between $A B$ infection/ 
colonization and previous antibiotic therapy, both at the level of individual use and at an ecological level in an ICU.

\section{FUNDING}

This study is part of a doctoral thesis that was supported by the Foundation for Health Research of Castilla - La Mancha [AN 2010/43].

\section{CONFLICTS OF INTEREST}

The authors declare that they have no conflicts of interest.

\section{REFERENCES}

1. Bergogne-Bérézin $\mathrm{E}_{1}$ Towner KJ. Acinetobacter spp. as nosocomial pathogens: microbiological, clinical, and epidemiological features. Clin Microbiol Rev 1996;9(2):148-65. doi: 10.1128/CMR.9.2.148165.1996.

2. Falagas $M E$, Karveli $E$. The changing global epidemiology of Acinetobacter baumannii infections: a development with major public health implications. Clin Microbiol Infect 2007;1: 117-9. PMID: 17328722

3. Fournier $P E_{1}$ Richet $H$. The epidemiology and control of Acinetobacter baumannii in health care facilities. Clin Infect Dis 2006;42(5):692-9. doi: 10.1086/500202.

4. Wilson SJ, Knipe CJ, Zieger MJ, Gabehart KM, Goodman JE, Volk HM et al. Direct costs of multidrug-resistant Acinetobacter baumannii in the burn unit of a public teaching hospital. Am J Infect Control 2004;32(6): 342-4. doi: 10.1016/j.ajic.2004.02.008.

5. Villegas MV, Hartstein Al. Acinetobacter outbreaks, 19772000. Infect Control Hosp Epidemiol 2003;24(4):284-95. doi: 10.1086/502205.

6. Peleg AY, Seifert H, Paterson DL. Acinetobacter baumannii: emergence of a successful pathogen. Clin Microbiol Rev 2008;21(3):53882. doi: 10.1128/CMR.00058-07.

7. Monterrubio-Villar J, González-Velasco C, Valdezate-Ramos S, Córdoba-López A, Villalón-Panzano P, Saéz-Nieto JA. Outbreak of multiresistant Acinetobacter baumannii in a polyvalent intensive care unit: clinical, epidemiological analysis and PFGE-printing evolution. Eur J Clin Microbiol Infect Dis 2009;28(10):1281-4. doi: 10.1007| s10096-009-0777-6.

8. Valencia R, Arroyo LA, Conde M, Aldana JM, Torres M-J, Fernán-

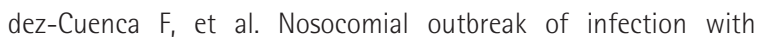
pan-drug-resistant Acinetobacter baumannii in a tertiary care university hospital. Infect Control Hosp Epidemiol 2009;30(3):257-63. doi: 10.1086/595977.

9. Torres HA, Vázquez EG, Yagüe G, Gómez JG. Multidrug resistant Acinetobacter baumanii: clinical update and new highlights. Rev Esp Quimioter 2010;23(1):12-9. PMID: 20232019

10. Horan TC, Andrus M, Dudeck MA. CDC/NHSN surveillance definition of health care-associated infection and criteria for specific types of infections in the acute care setting. Am J Infect Control
2008;36(5):309-32. doi: 10.1016/j.ajic.2008.03.002.

11. WHO Collaborating Centre for Drug Statistics Methodology, Guidelines for ATC classification and DDD assignment 2021. Oslo, Norway, 2020. Available at: https://www.whocc.no/filearchive/publications/2021_guidelines_web.pdf

12. Villalón $P$, Valdezate $S$, Medina-Pascual $M J$, Rubio $V$, Vindel $A$ Saez-Nieto JA. Clonal diversity of nosocomial epidemic Acinetobacter baumannii strains isolated in Spain. J Clin Microbiol 2011;49(3):875-82. doi: 10.1128/JCM.01026-10.

13. Magiorakos A-P, Srinivasan A, Carey RB, Carmeli Y, Falagas ME, Giske CG, et al. Multidrug-resistant, extensively drug-resistant and pandrug-resistant bacteria: an international expert proposal for interim standard definitions for acquired resistance. Clin Microbiol Infect 2012;18(3):268-81. doi: 10.1111/j.1469-0691.2011.03570.x.

14. Chen CH, Lin LC 1, Chang YJ, Chen YM, Chang CY, Huang CC.Infection Control Programs and Antibiotic Control Programs to Limit Transmission of Multi-Drug Resistant Acinetobacter baumannii Infections: Evolution of Old Problems and New Challenges for Institutes. Int J Environ Res Public Health 2015;12:8871-82; doi:10.3390/ijerph120808871

15. López-Lozano JM, Monnet DL, Yagüe A, Burgos A, Gonzalo N, Campillos $\mathrm{P}$, et al. Modelling and forecasting antimicrobial resistance and its dynamic relationship to antimicrobial use: a time series analysis. Int J Antimicrob Agents 2000;14(1):21-31. doi: 10.1016/ s0924-8579(99)00135-1.

16. Joly-Guillou M-L. Clinical impact and pathogenicity of Acinetobacter. Clin Microbiol Infect 2005;11:868-73. doi: 10.1111/j.14690691.2005.01227.x

17. Fournier $P E$, Richet $H$. The epidemiology and control of Acinetobacter baumannii in health care facilities. Clin Infect Dis 2006;42(5):692-9. doi: 10.1086/500202.

18. Bergogne-Bérézin E, Towner KJ. Acinetobacter spp. as nosocomial pathogens: microbiological, clinical, and epidemiological features. Clin Microbiol Rev 1996;9(2):148-65. doi: 10.1128/CMR.9.2.148165.1996.

19. Manikal VM, Landman D, Saurina G, Oydna E, Lal H, Quale J. Endemic carbapenem-resistant Acinetobacter species in Brooklyn, New York: citywide prevalence, interinstitutional spread, and relation to antibiotic usage. Clin Infect Dis 2000;31(1):101-6. doi: 10.1086/313902.

20. Husni RN, Goldstein LS, Arroliga AC, Hall GS, Fatica C, Stoller JK, et al. Risk factors for an outbreak of multi-drug-resistant Acinetobacter nosocomial pneumonia among intubated patients. Chest 1999;115(5):1378-82. doi: 10.1378/chest.115.5.1378.

21. del Mar Tomas $M$, Cartelle $M$, Pertega $S$, Beceiro a, Llinares $P$, Canle $D$, et al. Hospital outbreak caused by a carbapenem-resistant strain of Acinetobacter baumannii: patient prognosis and risk-factors for colonisation and infection. Clin Microbiol Infect 2005;11(7):540-6. doi: 10.1111/j.1469-0691.2005.01184.x.

22. Tsai H-T, Wang J-T, Chen C-J, Chang S-C. Association between antibiotic usage and subsequent colonization or infection of extensive drug-resistant Acinetobacter baumannii: a matched case-control study in intensive care units. Diagn Microbiol Infect 
Dis 2008;62:298-305. doi: 10.1016/j.diagmicrobio.2008.06.017.

23. Villers $D_{1}$ Espaze $E_{1}$ Coste-Burel $M$, Giauffret $F$, Ninin $E_{1}$ Nicolas $F$, et al. Nosocomial Acinetobacter baumannii infections: microbiological and clinical epidemiology. Ann Intern Med 1998;129(3):182-9. doi: 10.7326/0003-4819-129-3-199808010-00003.

24. Hsueh P-R, Teng L-J, Chen C-Y, Chen W-H, Yu C-J, Ho S-W, et al. Pandrug-resistant Acinetobacter baumannii causing nosocomial infections in a university hospital, Taiwan. Emerg Infect Dis 2002;8(8):827-32. doi: 10.3201/eid0805.020014.

25. Hsueh P-R, Chen W-H, Luh K-T. Relationships between antimicrobial use and antimicrobial resistance in Gram-negative bacteria causing nosocomial infections from 1991-2003 at a university hospital in Taiwan. Int J Antimicrob Agents 2005;26(6):463-72. doi: 10.1016/j.ijantimicag.2005.08.016.

26. Tóth $H$, Fésus A, Kungler-Gorácz O, Balázs B, Majoros L, Szarka K, et al. Utilization of vector autoregressive and linear transfer models to follow up the antibiotic resistance spiral in Gram-negative bacteria from cephalosporin consumption to colistin resistance. Clin Infect Dis 2019;69(8):1410-21. doi: 10.1093/cid/ciy1086.

27. López-Lozano JM, Lawes $T$, Nebot $C$, Beyaert $A$, Bertrand $X$, Hocquet $D$, et al; THRESHOLDS study group. A nonlinear time-series analysis approach to identify thresholds in associations between population antibiotic use and rates of resistance. Nat Microbiol 2019;4(7):116072. doi: 10.1038/s41564-019-0410-0.

28. Baran $G$, Erbay $A$, Bodur $H$, Ongürü $P$, Akinci $E$, Balaban $N$, et al. Risk factors for nosocomial imipenem-resistant Acinetobacter baumannii infections. Int J Infect Dis 2008;12(1):16-21. doi: 10.1016/j. ijid.2007.03.005.

29. Cisneros JM, Rodríguez-Baño J, Fernández-Cuenca F, Ribera A, Vila J, Pascual A, et al. Risk-factors for the acquisition of imipenem-resistant Acinetobacter baumannii in Spain: a nationwide study. Clin Microbiol Infect 2005;11(11):874-9. doi: 10.1111/j.14690691.2005.01256.x.

30. Tacconelli E, Cataldo MA, De Pascale G, Manno D, Spanu T, Cambieri $A$, et al. Prediction models to identify hospitalized patients at risk of being colonized or infected with multidrug-resistant Acinetobacter baumannii calcoaceticus complex. J Antimicrob Chemother 2008:62:1130-7. doi: 10.1093/jac/dkn289.

31. Rodríguez-Baño J, Garcia L, Ramírez E, Martínez-Martínez L, Muniain MA, Fernández-Cuenca $F$, et al. Long-term control of hospital-wide, endemic multidrug-resistant Acinetobacter baumannii through a comprehensive "bundle" approach. Am J Infect Control. 2009;37:715-22. doi: 10.1016/j.ajic.2009.01.008. 